\title{
AN ASSESSMENT OF PERCEPTION OF WASTE-PICKERS AND RISK- PROTECTIVE BEHAVIOUR FROM SELECTED DUMPSITES IN OGUN STATE NIGERIA
}

\author{
${ }^{1}$ Amosu, A. M. $\&^{* 2}$ Tella, A. \\ ${ }_{18 * 2}$ Department of Public Health, Babcock University, Ilishan Remo-Ogun State \\ *Corresponding Author's E-mail: ayotella1955@gmail.com Phone: +2348023070756
}

\begin{abstract}
Waste-pickers experience situations which place them at high risk of developing morbidities mainly external and internal injuries. The present study investigated the waste-pickers perception of waste-handling and risk-protective behavior from selected dumpsites in Ogun State, Nigeria. This study adopted a cross-sectional design and a multi-stage sampling technique, this was used to select 60 waste-pickers. A structured and validated questionnaire was used for data collection. Data was analyzed using descriptive statistics. Educated wastepickers had elementary education. The time interval of waste-picking ranged from 1 to 15 years. The majority of the waste-pickers had a poor perception of waste-handling. The majority of the waste-pickers had poor risk-protective behavior. Only $9(15 \%)$ reported using personal protective gears every time. The waste-pickers reported that they used the following PPEs; long sleeve shirt 46(22.0\%) and trousers 51(24.4\%). However, few used trousers 51(24.4\%); boot/shoe 43(20.6\%) and cap 24(11.5\%). Fifty percent of the waste-pickers reported that they washed up after the day's job. In conclusion, the waste-pickers had poor perception and poor risk-protective behavior. This study recommends that policy makers and charity organizations should educate waste-pickers on the importance of using protective gears and proper waste-handling.
\end{abstract}

Keywords: Nigeria, Ogun State, Perception, Risk-protective Behavior, Waste-handling, Waste-picker

LICENSE: This work by Open Journals Nigeria is licensed and published under the Creative Commons Attribution License 4.0 International License, which permits unrestricted use, distribution, and reproduction in any medium, provided this article is duly cited.

COPYRIGHT: The Author(s) completely retain the copyright of this published article.

OPEN ACCESS: The Author(s) approves that this article remains permanently online in the open access (OA) model.

QA: This Article is published in line with "COPE (Committee on Publication Ethics) and PIE (Publication Integrity \& Ethics)". 


\section{INTRODUCTION}

Waste-Pickering is a widespread and regular activity in nearly all cities in Sub-Saharan Africa. Waste-pickers are individuals who make a living by gathering and vending recyclable materials that have been thrown out by others (Nyathi et al., 2018). An estimate of $2 \%$ of the population in third world countries makes a living through wastepickering. Increased poverty due to unemployment in developing countries has resulted to scavenging (Ramos et al., 2013; Magaji \& Dakyes, 2011; Simatele \& Etambakonga, 2015).

Scavenging developed due to uncontrolled access to domestic bins (Afon, 2012). Individuals continue to scavenge because manufacturers offer a readymade market for their products with the likelihood of sustaining their needs (Nyathi et al., 2018). In the process, they make a significant contribution to environmental management in different cities and render services to the local economy (Dias, 2016).

However, scavenging poses serious health risks to the individuals involved. Scavengers are exposed to smoke as a result of burning of waste in the dumpsites leading to respiratory disorders (United Nations Environmental Programme [UNEP], 2013). Also, scavengers' activities such as hand picking of sharp objects could result to injuries as well as death in extreme cases, while others may be exposed to infections such as human immune deficiency virus (HIV) and hepatitis infection from hospital waste (Aboagye-Larbi et al., 2014)

Researchers have reported that waste-pickers experience conditions that place them at high-risk of developing both external and internal injuries such as being held in processing equipment; being knocked down by trucks; fires; explosions; being wounded by glass, contaminated syringe needles, health care waste and also death. They can also develop eye infections, stomach problems, typhoid fever, diarrhea, musculoskeletal disorders and carcinogenic effects (Chokhandre et al., 2017; Mol et al., 2017). Scavengers could as well become infected with skin and blood infections, eye and respiratory infections as a result of contact with polluted dust, wounds and insect bites, a skeletal disorder triggered by the lifting of heavy storage containers, and burns due to exposure with harmful chemicals combined with household waste (Magaji \& Dakyes, 2011; Afon ,2012).

A study conducted in India among waste-pickers who operated in three different cities reinforced these occupational health hazards. Emphasizing the lack of provisions of protective equipment, low income of the wastepickers, along with the ignorance of the workers as exacerbating risk factors to different types of external injuries. (Thakur et al., 2018). Waste-pickers often do not wear any protective equipment, and face great risks of injuries related to the type of material they are collecting (Awopetuet al., 2014). These waste pickers are susceptible to injuries due to lack of the necessary personal protective equipment (PPE) and thus are faced with pitiable working conditions.

Waste picking is therefore considered a dangerous occupation (Araújo, \& Tatiana, 2018). Researchers have suggested that PPE such as clothing, hand gloves, and walking boot should be given to waste-pickers to reduce infections and increase their efficiencies (Awopetu et al., 2014; Omosimua et al., 2020). However, the local and state governments are not providing any form of support to the waste pickers. Hence, this study assessed the perception of waste- pickers and risk-protective behavior from the selected dumpsites in Ogun State, Nigeria. 


\section{MATERIALS AND METHODS DESIGN AND STUDY POPULATION}

This is a cross-sectional study. The study population was waste-pickers working at Oke-Saje dumpsite and KotoAjala dump site in Ogun State.

\section{STUDY AREA AND STUDY LOCATION}

Ogun State was created on the 3rd of February, 1976. It was carved out of the old Western State of Nigeria and named after the Ogun River which runs across it from North to South. Situated between Latitude $6.20 \mathrm{~N}$ and $7.80 \mathrm{~N}$ and Longitude $3.0 \mathrm{oE}$ and $50 \mathrm{E}$, the state covers a total landmass of $16,409.26 \mathrm{sqkm}$. Abeokuta, the capital and largest urban center, is about 90 kilometers from Lagos and 740 kilometers from Abuja, the capital of Nigeria. The State is strategically located, bordered in the East by Ondo State, in the North by Oyo and Osun States and in the South by Lagos State and the Atlantic Ocean and in the West by Republic of Benin, which makes it an access route to the expansive markets of the Economic Community of West African States. There are twenty local government areas in this state. People in Ogun State are predominantly the Egbas, Ijebus, Yewas, Remos, and Aworis who belong to the main Yoruba ethnic group. It also has sub-groups, namely, Ketu, Ikale, Ilaje, Ohori, Anago, and Egun. There are eleven (11) dumpsites in Ogun State namely; Oke-Diya, Igberen, Hercules, Oke-Saje, Akinside, Ikoto, Koto-Ajala, Onigbedu, Ogere, Onaegbo and Agbara.

Oke-Saje dumpsite covering 46.072 acres is in Abeokuta South LGA in Ogun state. It is the largest dumpsite with about 150 tons of wastes dumped on a daily basis. All these wastes emanate from Abeokuta South LGA, Abeokuta North LGA, Odeda LGA and part of Ewekoro LGA. Its location in Ogun state capital with high population, urban and especially high commercial activities account for high turn-in of waste which keeps waste-pickers busy daily and qualifies it as the most ideal site for a recycling plant.

Koto-Ajala dump site covering over 10 acres is in Owode-Egba (off Siun road), Obafemi-Owode LGA. All wastes from Siun, Mowe, Ogere, and Sagamu interchange are dumped here. Apart from Obafemi-Owode, it serves part of Ikenne and part of Sagumu LGAs. The strategic location of this site makes it the choice for industries like Nestle, Flour Mills, Apple and Pears to dump their wastes (See figure 1)

\section{SAMPLE TECHNIQUE}

Thirty waste-pickers each were selected using a multi-stage sampling technique from the two dumpsites. Wastepickers who were within 16-65 years, have worked for minimum of six months and were willing to participate were recruited for this study.

\section{INSTRUMENT FOR DATA COLLECTION}

Data was collected using structured questionnaires. The data collection tools were pre-tested in Oke-Diya dumpsite in Sagamu which is different from the study site. The pre-test data was assessed, analyzed and any necessary adjustments were made before proceeding to the intended sites for the real study. The questionnaire had three sections. Section A, addressed demography, marital status, education levels, and income, while the Section B dealt 
with waste-pickers' perception of risk-protective behavior. Section C focused on waste-pickers risk-protective behavior.

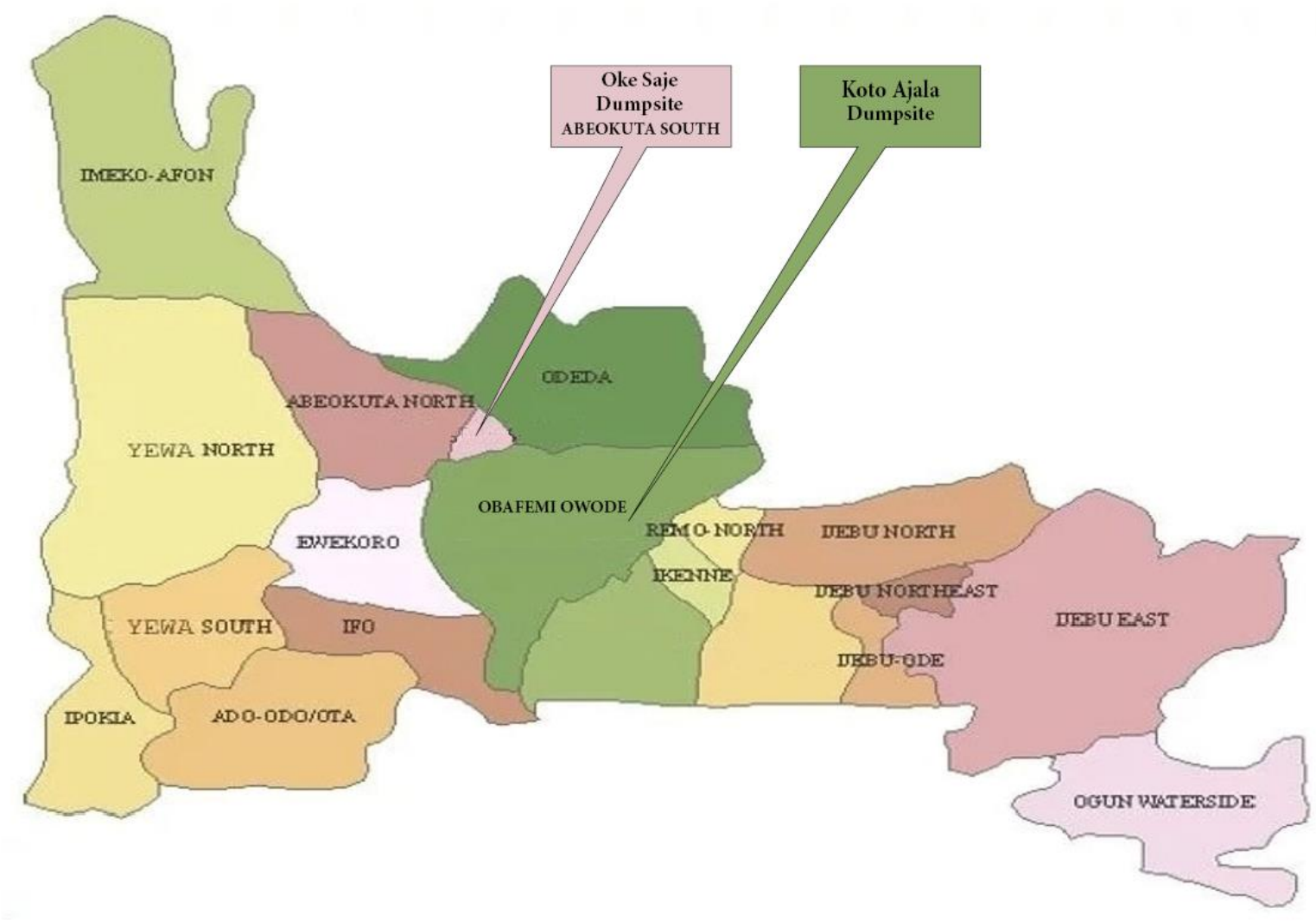

Figure 1: Map of Ogun State showing the Dumpsites

On arrival at the dumpsites, permission to administer the questionnaire was obtained from the dumpsites manager and the association chairman of the waste-pickers. The questionnaire was administered to scavengers who were willing to participate. Sixty waste-pickers selected randomly from the two dumpsites filled the questionnaire.

\section{ETHICAL ISSUES AND CONFIDENTIALITY}

Written approvals from Babcock University Health Research Committee (BUHREC) and Ogun State Waste Management Authority (OGWAMA) were obtained, indicating that an academic research study within Oke-Saje and Koto-Ajala dumpsites was to be done. Only waste-pickers who agreed to participate voluntarily were interviewed. To ensure confidentiality throughout the study period, only code numbers were used instead of the waste-pickers names.

\section{DATA PROCESSING AND ANALYSIS}

The data obtained from completed copies of the questionnaire were cleaned, coded and entered into Microsoft Excel spread sheet and transferred to Statistical Package for Social Scientists (SPSS) version 21.0 for analysis. The analysis involved descriptive statistics such as measures of dispersion and central tendency like mean, standard deviations. 
The perception section was measured on a 10-point rating scale. One (1) point was assigned for the positive statements, while zero (0) point for negative statements. All individual score was summed up. Possible score ranged between $0-10$. Those who obtained score $<5$ were regarded as having low perception while those who scored $\geq 5$ were regarded as having high perception.

\section{RESULTS}

\section{SOCIO-DEMOGRAPHIC OF THE WASTE-PICKERS}

The mean age of the waste-pickers was $27.58 \pm 5.2$ years. Almost half $(46.7 \%)$ of the waste-pickers were within the 24-29 age bracket. All the waste-pickers were male. More than half (55\%) of the waste-pickers were married. Most (75.0\%) of the waste-pickers were Muslim. More than half (53.3\%) of the waste-pickers had primary education. More than half (60.0\%) of the waste-pickers had worked between 6-10 years. Most of the waste-pickers worked for 7 days per week and 6 to 10 hours per day. Some (8.8\%) live in rented accommodation, a few (1.7\%) owned house, while others (3.3\%) either lived with family or friends. However, the majority $(86.7 \%)$ of them resided in temporary shelters in the vicinity of the dumpsite (See, Table 1).

\section{WASTE-PICKERS PERCEPTION OF RISK-PROTECTION BEHAVIOR}

More than half (51.3\%) of the waste-pickers disagreed that solid waste can affect one only by touching it. The majority (73.4\%) of the waste-pickers disagreed that their work exposes them to disease. Most (60\%) of the waste-pickers agreed that by wearing gloves they can be protected from exposure to disease. More than half $(53.3 \%)$ of the wastepickers disagreed that it is important to bathe and clean up after exposure to solid waste. More than half (53.3\%) of the waste-pickers disagreed that using personal protective equipment is unnecessary. Most (53.3\%) of the wastepickers disagreed that solid wastes from the hospital and household pose the same risk. Fifty percent of the wastepickers agreed that getting injured during work is part of the risk of the job. Likewise, half (50.0\%) of the wastepickers disagreed that it is not necessary to wear long sleeve shirt and long pants. The majority (73.3\%) of the wastepickers agreed that they self-medicate to save money and time rather than going to the hospital to get treatment whenever they are injured. Most (76.7\%) of the waste-pickers see nothing wrong in sleeping on the dumpsite (See, Table 2).

Furthermore, the waste-pickers perception measured on a 10-point rating scale showed a mean score of $3.5 \pm 1.36$. The majority $(85.0 \%)$ of the waste-pickers had a poor perception of solid waste-handling while a few (15\%) had high perception of solid waste handling (See, Table 2). 
Table 1: Socio-demographic Characteristics of the Waste-Pickers

\begin{tabular}{|c|c|c|}
\hline Variables & Frequency $(n=60)$ & Percentage (\%) \\
\hline \multicolumn{3}{|l|}{ Age in years (mean age $27.6 \pm 5.1)$} \\
\hline $18-23$ & 14 & 3.3 \\
\hline $24-29$ & 28 & 46.7 \\
\hline $30-35$ & 14 & 23.4 \\
\hline $36-41$ & 2 & 3.3 \\
\hline $42-47$ & 2 & 3.3 \\
\hline \multicolumn{3}{|l|}{ Gender } \\
\hline Male & 60 & 100.0 \\
\hline \multicolumn{3}{|l|}{ Marital status } \\
\hline Single & 27 & 45.0 \\
\hline Married & 33 & 55.0 \\
\hline \multicolumn{3}{|l|}{ Religion } \\
\hline Islam & 45 & 75.0 \\
\hline Christian & 15 & 25.0 \\
\hline \multicolumn{3}{|l|}{ Educational level } \\
\hline No formal education & 21 & 35.0 \\
\hline Primary & 32 & 53.3 \\
\hline Secondary & 4 & 6.7 \\
\hline Tertiary & 3 & 5.0 \\
\hline \multicolumn{3}{|l|}{ Years of Service } \\
\hline$\leq 5$ & 13 & 21.6 \\
\hline $6-10$ & 36 & 60.0 \\
\hline$>10$ & 11 & 18.4 \\
\hline \multicolumn{3}{|l|}{$\begin{array}{l}\text { Numbers of working days per } \\
\text { week }\end{array}$} \\
\hline 1 & 1 & 1.7 \\
\hline 6 & 5 & 8.3 \\
\hline 7 & 54 & 90.0 \\
\hline \multicolumn{3}{|l|}{$\begin{array}{l}\text { Number of working hours per } \\
\text { day }\end{array}$} \\
\hline $0-5$ & 5 & 8.4 \\
\hline $6-10$ & 55 & 91.6 \\
\hline \multicolumn{3}{|l|}{ Where they lived } \\
\hline Rented apartment & 5 & 8.3 \\
\hline Lived with family/friends & 2 & 3.3 \\
\hline Own home & 1 & 1.7 \\
\hline Temporary shelter in the dumpsite & 52 & 86.7 \\
\hline
\end{tabular}

\section{WASTE-PICKERS RISK-PROTECTIVE BEHAVIOR}

All the waste-pickers reported that they had personal protective equipment. However, only (15\%) reported using the PPE every-time. The waste-pickers reported that they use the following PPEs Cap (11.5\%); Boot/shoe (20.6\%); long sleeve shirt (22.0\%) and long trouser (24.4\%) (See figure 2). Less than half (41.7\%) of the waste-pickers reported they do other activities without washing their hand hands. Few (31.7\%) of the waste-pickers reported that they washed their clothes immediately after the day's job. Half of the waste-pickers reported that they walked through the refuse dump bare footed and work with their bare hands. Also, fifty percent of the waste-pickers reported that they took their bathe after the day's job. Less than half (43.3\%) of the waste-pickers reported that they clean their equipment every time.The majority (61.7\%) of the waste-pickers reported that once they get injured on the job they bandage it. Less 
than half $(46.7 \%)$ of the waste-pickers reported that they eat on dumpsite every time. The majority $(63.3 \%)$ of the waste pickers reported that whenever they had an injury they just continue with their work. Less than half (46.7\%) of the waste-pickers reported that they used their fingers to touch their eyes every time while collecting solid waste (See, Table, 3).

Table 2: Waste-Pickers Perception of Risk-Protective Behavior

\begin{tabular}{llll}
\hline S/N & Perception Statements & $\begin{array}{l}\text { Agree } \\
\mathrm{N}(\%)\end{array}$ & $\begin{array}{l}\text { Disagree } \\
\mathrm{N}(\%)\end{array}$ \\
\hline 1 & Danger from solid waste can affect us in only one way which is by & $29(48.4)$ & $31(51.3)$ \\
& $\begin{array}{l} \\
\text { touching it. }\end{array}$ & $16(26.6)$ & $44(73.4)$ \\
2 & My work does not expose me to any disease. & $36(60.0)$ & $24(40.0)$ \\
3 & Just wearing groves can protect disease from solid waste exposure & $8(46.7)$ & $32(53.3)$ \\
4 & It is important to bathe and clean up after exposure to solid waste & $28(46.7)$ & $32(53.3)$ \\
5 & Using personal protective equipment is unnecessary & $28(46.7)$ & $32(53.3)$ \\
6 & Solid wastes from the hospital and household pose the same risk & $30(50.0)$ & $30(50.0)$ \\
7 & It is normal to get injured during work, it is part of the risk of the job & $30(50.0)$ & $30(50.0)$ \\
8 & It is not necessary to wear long sleeve shirt and long pant & $44(73.3)$ & $16(26.7)$ \\
9 & When you are injured during work, buying some drug saves money and & & \\
& time rather than going to the hospital & $46(76.7)$ & $14(23.3)$ \\
10 & There is nothing wrong in taking a rest and sleeping on the dumpsite. & & \\
& Mean perception 3.5 \pm 1.36 & $51(85.0)$ & \\
& Low perception < 5 & $9(15.0)$ & \\
\hline & High perception $\geq 5$ & &
\end{tabular}

Table 3: Waste-Pickers Risk Protective Behavior

\begin{tabular}{|c|c|c|c|}
\hline Items & Never $(\%)$ & Sometimes (\%) & Every time (\%) \\
\hline How often do you use PPE & $6(10)$ & $45(75)$ & $9(15)$ \\
\hline $\begin{array}{l}\text { After collecting solid waste, I do other activities } \\
\text { without washing my hands }\end{array}$ & $34(56.7)$ & $1(1.6)$ & $25(41.7)$ \\
\hline After collecting solid waste, I wash my clothes & $40(66.7)$ & $1(1.6)$ & $19(31.7)$ \\
\hline $\begin{array}{l}\text { I walk and work through the refuse dump with bare } \\
\text { foot and bare hands }\end{array}$ & $20(33.3)$ & $10(16.7)$ & $30(50)$ \\
\hline $\begin{array}{l}\text { I take a bath immediately after I am exposed to } \\
\text { solid waste }\end{array}$ & $29(48.4)$ & $1(1.6)$ & $30(50.0)$ \\
\hline I clean my equipment after finishing my work & $24(40.0)$ & $10(16.7)$ & $26(43.3)$ \\
\hline $\begin{array}{l}\text { When a wound appears on my body, I do not put a } \\
\text { bandage on it }\end{array}$ & $21(35.0)$ & $2(3.3)$ & $37(61.7)$ \\
\hline I do eat food in my workplace & $24(40.0)$ & $8(13.3)$ & $28(46.7)$ \\
\hline When I get hurt, I just continue with work & $17(28.3)$ & $5(8.3)$ & $38(63.3)$ \\
\hline $\begin{array}{l}\text { I use my finger to touch my eyes while collecting } \\
\text { solid waste }\end{array}$ & $19(31.7)$ & $13(21.7)$ & $28(46.7)$ \\
\hline
\end{tabular}




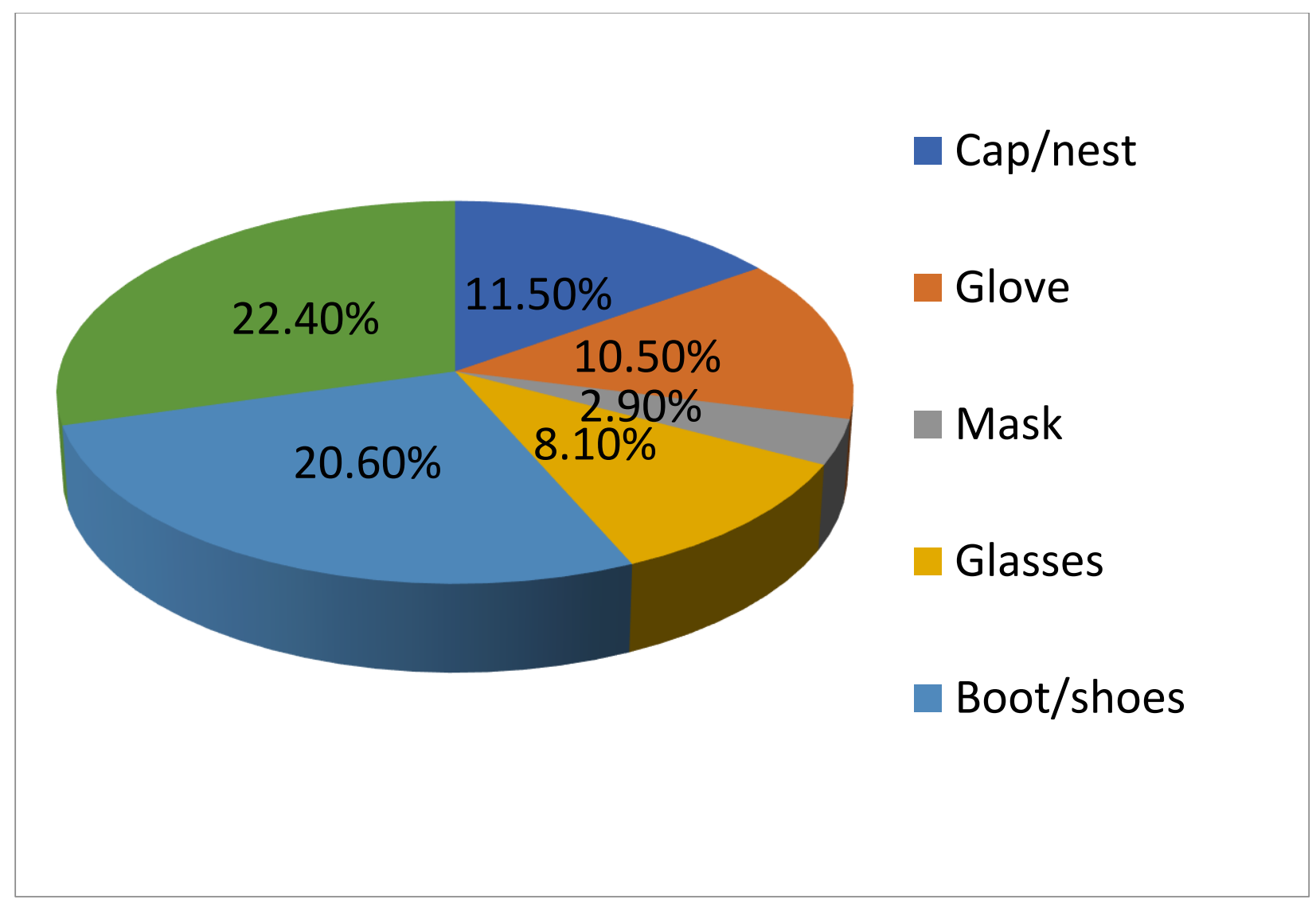

Figure 2: Types of Personal Protection Equipment used by Waste-pickers

\section{DISCUSSION}

This study revealed that all the respondents were male. This is similar to the findings of a study conducted in Abuja which shown that the practice was mainly operated by males (Magaji \& Dakyes, 2011). However, this result is at variance with a study conducted at Onderstepoort dumpsite in South Africa where it was stated that both males and females engaged in the business of waste picking (Nyathietal.,2018). This disparity in result may be as a result of the differences in the study area. The study showed that more than half of the respondents only had primary education. These findings conform to those of Simatele \& Etambakonga (2015), where they reported that the highest level of education attained by the scavengers was primary school. Contrary to this study, was a study in South Africa where majority of the respondent's attained secondary educational status (Nyathi et al., 2018). This result showed that most of the respondents lived in a temporary shelter in the vicinity of the dumpsite. This was contrary to the findings by Nyathi et al. (2018) where they reported that only a few lived in a temporary shelter in the dumpsite.

This study revealed that the respondents had low perception as the interviews conducted showed that only a small proportion of the waste-pickers responded in the affirmative that their work exposes them to diseases. Also, a little more than half of the waste-pickers rejected the notion that it is important to bathe and clean up after exposure to waste. This report was similar to the report of the male respondents in a South African study, but was in disparity to the female respondents of the same study (Nyathi et al., 2018). Few of the waste-pickers interviewed responded 
positively that solid wastes from the hospital and household pose the same risk. A good proportion of the wastepickers responded that getting injured during work is part of the hazard of the job. Also, half of the respondents interviewed had the notion that it is not necessary to wear long sleeve shirt and long pants (trousers). These findings were similar to a study conducted in Thailand by Thurarattanasunthon et al., (2012), where they reported that wastepickers were exposed to injuries at work due to a lack of awareness of the significance of wearing protective clothing.

This study showed that few of the respondents used the PPE every-time. This is similar to the findings reported in South Africa (Nyathi et al, 2018). This is also at par with the finding of a study in Thailand by Thurarattanasunthon et al., (2012). The study revealed poor risk-protective behavior amongst the respondents as only a few reported washings their cloth after the day's job. This finding corroborates the findings of Nyathi et al., (2018).

\section{CONCLUSION}

The waste-pickers had a poor perception of waste-handling and poor risk-protective behavior. This is not surprising as most of the waste-pickers had only primary education coupled with the fact that no governmental support in terms of education on proper waste handling and the risk associated with improper waste handling. This lackadaisical attitude from the government may be responsible for their low perception on the dangers associated with improper wastehandling.

\section{RECOMMENDATION}

The researchers recommended that government or non-governmental organizations should conduct health promotion programs targeting waste-pickers by enlightening them on how to handle waste and the importance of protective clothing to improve their risk-protective behavior. Also, protective equipment such as boots and hand gloves should be provided at a subsidized rate to the waste-pickers to promote its usage.

\section{LIMITATION OF THE STUDY}

Few waste-pickers were willing to participate in the study due to fear of breaking rules and regulations of the dumpsite. This resulted in few participants as most were not certain that their chairman approved the study. Others were afraid of the law enforcement agencies thinking that they were conducting an investigation on waste-pickers, hence they did not cooperate.

\section{CONFLICT OF INTEREST}

The authors declare that they have no conflict of interest. 


\section{REFERENCE}

Aboagye-Larbi, H., Acheampong, M., Kye, S., \& Carboo, D (2014). The potential health hazards associated with waste scavenging in Ghana: a case study of three selected dumpsites in Tema Metropolis. International Journal of Environmental Science and Toxicology Research, 2 (10): 199-209.

Afon, A. (2012). A survey of operational characteristics, socioeconomic and health effects of scavenging activity in Lagos, Nigeria.Waste Management and Research, 30(7): 664-671

Araújo, N.C, \& Tatiana, S. (2018). A descriptive study of work ability and health problems among Brazilian recyclable waste pickers. Journal of Community Health, 43(2): 366-371.

Awopetu, M.S., Awopetu, R.G., Sample, E.D., Olufiropo, A.O., Awokola, S., Fullen, M.A., \& Hammond, F.N. (2014). Municipal solid waste management and the role of waste-pickers in Nigeria.International Journal of Education Research, 2: 1-12.

Chokhandre, P., Singh,S., \& Kashyap, G.(2017). Prevalence, predictors and economic burden of morbidities among waste-pickers of Mumbai, India: A cross-sectional study. Journal of Occupation Medical Toxicology, 2:1-8.

Dias, S. (2016). Waste pickers and cities. Journal of Environmental and Urbanization, 28(2): 375-390. doi: $101177 / 0956247816657302$

Jayakrishnan,T., Jeeja, M., \& Bhaskar, R.(2013). Occupational health problems of municipal solid waste management workers in India.International Journal Environmental Health Engineering, 2: 23-42.doi: 10.4103/22779183.122430

Magaji, J., \& Dakyes, S. (2011). An assessment of socio-economic impact of waste scavenging as a means of poverty alleviation in Gwagwalada, Abuja.Selected works of confluence.Journal Environmental Studies, 6(1): 4256.

Mol, M.P., Pereira, A.F., Greco, D.B., Cairncross, S., \& Heller, L. (2017). Assessment of work-related accidents associated with waste handling in Belo Horizonte (Brazil). Waste Management Research, 35(10): 10841092.doi: 10.1177/0734242X17722209

Muhammad, M., \& Manu, H (2013). Gender roles in informal solid waste management in cities of northern Nigeria: a case study of Kaduna metropolis, Academic Research, 4(5):142-153.

Nyathi, S., Olowoyo, J., \& Oludare, A. (2018). Perception of scavengers and occupational health hazards associated with scavenging from a waste dumpsite in Pretoria, South Africa. Journal of Environmental and Public Health, 1-7. https://doi.org/10.1155/2018/9458156

Omosimua, I., Oluranti,O., Obindah, G., \& Busayo, A.(2020).Working Conditions and Career Aspirations of Waste Pickers in Lagos State. Recycling, 6,1-7. https:// doi.org/10.3390/recycling6010001 
Ramos,N., De Castilhos, A., Forcellini, F., \& Graciolli, O. (2013). Profile study of waste pickers in Brazil: requirements for the development of a collection vehicle and optimized routing. Journal of Urban and Environmental Engineering, 7(2), 231-246.

Simatele,D., \& Etambakonga, C (2015). Scavenging for solid waste in Kinshasa: a livelihood strategy for the urban poor in the Democratic Republic of Congo, Habitat International, 49:266-274.doi: 10.1016/j.habitatint.2015.05.029

Thurarattanasunthon, P., Siriwong, W., Robson, M., \& Borjan, M (2012). Health risk reduction behaviours model for scavengers exposed to solid waste in municipal dump sites in NakhonRatchasima Province, Thailand. Risk Management and Health Care Policy, 5: 97-104.

United Nation Environmental Programme, (2013). Municipal Solid Waste Open Dump Site Juba, South Sudan, UNEP, Nairobi, Kenya. Retrieved on June 16, 2021 https://wedocs.unep.org/20.500.11822/19538 